\title{
Predictors of massive transfusion with thoracic aortic procedures involving deep hypothermic circulatory arrest
}

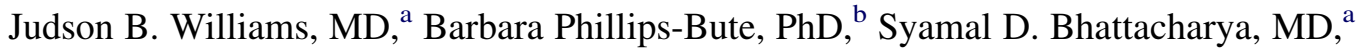 \\ Asad A. Shah, MD, ${ }^{a}$ Nicholas D. Andersen, MD, ${ }^{a}$ Burak Altintas, MD, ${ }^{a}$ Brian Lima, MD, ${ }^{a}$ \\ Peter K. Smith, MD, ${ }^{a}$ G. Chad Hughes, MD, ${ }^{a}$ and Ian J. Welsby, MBBS ${ }^{b}$
}

\begin{abstract}
Objective: Massive perioperative blood product transfusion may be required with thoracic aortic operations and is associated with poor outcomes. We analyzed independent predictors of massive transfusion in thoracic aortic surgical patients undergoing deep hypothermic circulatory arrest.
\end{abstract}

Methods: The study consisted of 168 consecutive patients undergoing open thoracic aortic procedures involving
deep hypothermic circulatory arrest between July 2005 and August 2008 . We identified 26 preoperative and pro-
cedural variables as potentially related to blood product use, tested for association with total blood products
transfused by multivariate linear regression model, and constructed logistic regression model for massive trans-
fusion (requiring $\geq 5$ units of transfused packed red blood cells between incision and 48 postoperative hours).

Results: Multivariate linear regression determined that 6 significant variables accounted for $42 \%$ of variation in total blood products transfused: age $(P=.008)$, preoperative hemoglobin $(P=.04)$, weight $(P=.02)$, cardiopulmonary bypass time $(P<.0001)$, emergency status $(P<.0001)$, and resternotomy $(P<.0001)$. Final predictive logistic regression model included $1-\mathrm{g} / \mathrm{dL}$ increase in preoperative hemoglobin (odds ratio, $0.54 ; 95 \%$ confidence interval, $0.43-0.69 ; P<.0001$ ), 10 -minute increase in cardiopulmonary bypass time (odds ratio, $1.15 ; 95 \%$ confidence interval, $1.05-1.26 ; P=.0026$ ), and emergency status (odds ratio, $4.02 ; 95 \%$ confidence interval, $1.53-10.55 ; P=.0047$.

Conclusions: Cardiopulmonary bypass time, emergency status, and preoperative hemoglobin were independent predictors of massive transfusion. These variables, along with weight, age, and resternotomy, were associated with total blood product use in thoracic aortic operations involving deep hypothermic circulatory arrest. (J Thorac Cardiovasc Surg 2011;141:1283-8)

Massive perioperative transfusion may occur with thoracic aortic operations. Although there is certainly no substitute for meticulous surgical technique, the etiology of unusually high transfusion requirement is often multifactorial. Hemostatic derangements in aortic surgery are caused by a multitude of interrelated factors, including interference with the vascular integrity, surgical dissection, deep hypothermic circulatory arrest (DHCA), ischemia and reperfusion, dilution of coagulation factors from large-volume fluid resuscitation, transient need for heparinization, and the use of cardiopulmonary bypass (CPB). ${ }^{1}$ Patient-level factors include age, sex, diabetes, preoperative hemoglo-

\footnotetext{
From the Division of Cardiovascular and Thoracic Surgery, ${ }^{a}$ Department of Surgery, and the Division of Cardiothoracic Anesthesia, ${ }^{b}$ Department of Anesthesiology, Duke University Medical Center, Durham, NC.

Supported by National Institutes of Health training grant number T32-HL069749 and the National Heart, Lung, and Blood Institute-sponsored Cardiothoracic Surgical Trials Network, grant number U01-HL088953 (to J.B.W.).

Disclosures: Authors have nothing to disclose with regard to commercial support.

Received for publication Jan 28, 2010; revisions received June 17, 2010; accepted for publication July 5, 2010; available ahead of print Dec 17, 2010.

Address for reprints: Ian J. Welsby, MBBS, Department of Anesthesiology, Duke University Medical Center, DUMC Box 3094, Durham, NC 27710 (E-mail: welsb001@mc.duke.edu).

$0022-5223 / \$ 36.00$

Copyright (C) 2011 by The American Association for Thoracic Surgery

doi:10.1016/j.jtcvs.2010.07.098
}

bin, platelets, prothrombin time, and partial thromboplastin time. ${ }^{2-4}$

There are few clinical data addressing predictors of massive transfusion specific to operations for disease of the thoracic aorta, particularly those involving DHCA. ${ }^{5,6}$ The DHCA used for neuroprotection in thoracic aortic surgery slows coagulation cascade activity, reduces coagulation factor synthesis, increases fibrinolysis, decreases platelet count, and impairs platelet function. ${ }^{7}$ The prosthetic grafts used for aortic repair consume platelets and other factors. ${ }^{8}$ Aortic disease itself may also predispose toward coagulopathy through the exposure of tissue factor and other mechanisms. ${ }^{9,10}$

Adverse outcomes attributable to the sequelae of massive perioperative transfusion are well recognized in the cardiac surgical literature, including a strong independent association with mortality. ${ }^{11,12}$ Identification of patients at high risk for requiring massive transfusion not only will allow improved risk stratification and preoperative counseling but also may create an opportunity for therapeutic modalities targeted toward individual patients in the perioperative period. Our objective was to determine the predictors of massive perioperative transfusion with open thoracic aortic procedures involving DHCA. We therefore tested the hypothesis that patient and procedural 


\author{
Abbreviations and Acronyms \\ $\mathrm{CPB}=$ cardiopulmonary bypass \\ DHCA $=$ deep hypothermic circulatory arrest \\ $\mathrm{IQR}=$ interquartile range \\ PRBCs $=$ packed red blood cells
}

characteristics could be used to model the need for transfusion with thoracic aortic surgery.

\section{MATERIALS AND METHODS Data Source}

The Duke Thoracic Aortic Surgery Database is a prospectively maintained, comprehensive clinical registry of all patients who have undergone any thoracic aortic procedure at Duke University Medical Center (Durham, NC) since 2005. This study included all patients who underwent a thoracic aortic procedure with DHCA between July 2005 and August 2008, excluding only patients who underwent a separate procedure in the perioperative period that resulted in massive transfusion. All procedures were performed by a single surgeon (G.C.H.), thus minimizing the contribution of variation in surgical technique to the findings. This study was approved by the Duke University institutional review board, which waived the need for individual patient consent. The Duke Thoracic Aortic Surgery Database provided baseline characteristics, clinical variables, and surgical procedure details. Review of individual medical records was undertaken to complete any missing clinical data points, and blood bank records provided precise information regarding amounts of blood products administered.

\section{Conduct of Procedures and Anesthesia}

Nonpulsatile CPB was conducted for each case with a membrane oxygenator after a crystalloid and mannitol prime and with an arterial line filter. Porcine heparin was administered as a bolus of $300 \mathrm{U} / \mathrm{kg}$ and supplemented to maintain an activated clotting time longer than 480 seconds. A 5000-unit bolus of heparin was given before circulatory arrest. During CPB, temperature-adjusted flow rates of $2.5 \mathrm{~L} /\left(\mathrm{min} \cdot \mathrm{m}^{2}\right)$ were used, and mean arterial pressure was generally maintained between 50 and $70 \mathrm{~mm} \mathrm{Hg}$. Anesthesia was maintained with isoflurane $(0.5 \%-1.0 \%)$ by the oxygenator. Alpha stat management was used for maintenance of normal $\mathrm{pH}, \mathrm{Po}_{2}$, and $\mathrm{PCO}_{2}$ values. Antegrade and retrograde cold blood cardioplegic solutions were used for myocardial protection. Our institutional preference is to perform open thoracoabdominal (extent I-III) and descending aortic aneurysm repairs with DHCA.

Before the portion of the aortic reconstruction requiring DHCA, the patient was cooled on CPB until electrocerebral inactivity was detected by electroencephalography by previously described techniques ${ }^{13}$; electrocerebral inactivity was usually reached at a nasopharyngeal temperature between $14^{\circ} \mathrm{C}$ and $18^{\circ} \mathrm{C}$. Once electrocerebral inactivity was achieved through hypothermia, the circulation was stopped. Antegrade cerebral perfusion $(5-15 \mathrm{~mL} /[\mathrm{kg} \cdot \mathrm{min}])$ was typically used for adjunct cerebral perfusion during the period of systemic DHCA. After aortic reconstruction, CPB was reinstituted, and the patient was gradually rewarmed to a normal temperature after a 5-minute period of cold reperfusion for free radical washout. Four units of fresh-frozen plasma were typically added to the circuit to ensure adequate anticoagulant factors during DHCA. A hematocrit of 0.18 to 0.20 was generally acceptable during $\mathrm{CPB}$, although this was increased to more than 0.20 for separation from CPB. Protamine sulfate was administered after separation from $\mathrm{CPB}$ to reverse heparin anticoagulation until the activated clotting time returned to baseline or the ratio of $1 \mathrm{mg}$ to 100 units of heparin was reached. We maintained a general approach of avoiding unnecessary use of blood products, which were not administered unless bleeding or anemia was observed. After separation from CPB, red blood cells were transfused according to the patient's preoperative condition, volume status, and hemoglobin concentration.

Standard practice included intraoperative administration of an antifibrinolytic therapy. Before its withdrawal from the US market, aprotinin (Bayer Corporation, West Haven, Conn) was used (2-MKIU bolus and 0.5 -MKIU/h infusion until bleeding cessation). Subsequently, $\epsilon$-aminocaproic acid was administered as a $10-\mathrm{g}$ bolus followed by a $1-\mathrm{g} / \mathrm{h}$ infusion, with an additional 5-g bolus before separation from CPB to account for that lost during hemofiltration, which was performed in all cases to remove excess crystalloid before separation from $\mathrm{CPB}$. The return of washed, shed red blood cells (BRAT II blood cell salvage machine; Cobe Cardiovascular Inc, Arvada, Colo) to the patient was routine. Transfusion decisions in the perioperative period were aided by local guidelines and use of chest tube output, activated clotting time, platelet count, fibrinogen level, thromboelastography, prothrombin time, and partial thromboplastin time, as recommended by the American Society of Anesthesiologists published guidelines. ${ }^{14}$ Clopidogrel and other $\mathrm{P}_{2} \mathrm{Y}_{12}$ inhibitors, regardless of dose, were withheld 7 days before the operation. Aspirin $(325 \mathrm{mg}$ ) was withheld 5 days before the operation. Aspirin $(81 \mathrm{mg})$ was not withheld before the operation. All antiplatelet agents were restarted at preoperative dosages on postoperative day 1 unless active bleeding was present.

\section{Outcome Measures}

The 26 candidate variables for the analysis included age, sex, race, American Society of Anesthesiologists grade, diabetes, preoperative creatinine level, warfarin (Coumadin) use, partial thromboplastin time, platelet count, international normalized ratio, hemoglobin concentration, weight, height, body surface area, blood pressure, aprotinin use, previous cardiac surgical procedure, emergency status, concomitant cardiac procedure, total arch versus hemiarch repair, thoracoabdominal aortic aneurysm type, aortic crossclamp time, cerebral circulatory arrest time (period when brain was receiving less than $100 \%$ of normal cerebral blood flow, including antegrade or retrograde cerebral perfusion), systemic circulatory arrest time (period during which lower body was not perfused, longer than cerebral circulatory arrest time for total arch replacement and open descending or thoracoabdominal aortic repairs and equal to cerebral circulatory arrest time for hemiarch repairs), and CPB time. Allogeneic blood product use included all products given from the time of incision through postoperative days 0,1 , and 2 , including any given at the time of return to the operating room for bleeding. Volume of intraoperative blood cell salvage machine transfusion was not included in this calculation, because this blood is not allogeneic. Considering the need for massive transfusion as a dichotomous outcome, we used a previously described definition of massive transfusion. ${ }^{11}$ Patients who received at least 5 units of packed red blood cells (PRBCs) were defined as having had massive transfusion.

\section{Statistical Analysis}

Patient and operative characteristics are summarized according to presence or absence of massive transfusion. Table 1 presents categoric variables as percentages; continuous variables are presented as mean $\pm \mathrm{SD}$ unless otherwise stated. For comparisons, the Wilcoxon rank sum test was used for continuous variables, and the $\chi^{2}$ test was used for categoric variables, with an alternative hypothesis that the rates across columns were not equal.

We evaluated the association of patient and procedural characteristics with the need for transfusion in 2 ways. Primarily, a linear regression model was developed with total blood products transfused as the outcome variable. Total blood products included all allogeneic products from the case start time through 48 postoperative hours. Because blood product use was not normally distributed, a $\log$ transform was performed before 
TABLE 1. Patient characteristics and operative variables

\begin{tabular}{|c|c|c|c|c|}
\hline Characteristic & Overall $(n=168)$ & MT $(n=49)$ & No MT $(n=119)$ & $P$ value \\
\hline Age (y) & $57.4 \pm 14.2$ & $60.6 \pm 15.5$ & $56.1 \pm 13.4$ & .06 \\
\hline Female & $29 \%(49)$ & $38 \%(18)$ & $25 \%(30)$ & .09 \\
\hline Nonwhite & $6 \%(10)$ & $9 \%(4)$ & $5 \%(6)$ & .27 \\
\hline American Society of Anesthesiologists grade & $3.5 \pm 0.5$ & $3.8 \pm 0.4$ & $3.4 \pm 0.5$ & $<.0001$ \\
\hline Diabetes & $3 \%(5)$ & $4 \%(2)$ & $2 \%(3)$ & .66 \\
\hline Preoperative creatinine $(\mathrm{mg} / \mathrm{dL})$ & $1.3 \pm 1.3$ & $1.6 \pm 1.8$ & $1.2 \pm 0.9$ & .11 \\
\hline Preoperative warfarin & $16 \%(26)$ & $20 \%(10)$ & $14 \%(16)$ & .31 \\
\hline Preoperative partial thromboplastin time (s) & $32.6 \pm 9.6$ & $31.5 \pm 9.6$ & $33.1 \pm 9.7$ & .32 \\
\hline Preoperative platelets $\left(10^{9}\right.$ cells $\left./ \mathrm{L}\right)$ & $214.6 \pm 58.1$ & $216.1 \pm 62.2$ & $213.9 \pm 56.5$ & .82 \\
\hline Preoperative international normalized ratio & $1.05 \pm 0.16$ & $1.12 \pm 0.26$ & $1.03 \pm 0.09$ & .001 \\
\hline Preoperative hemoglobin $(\mathrm{g} / \mathrm{dL})$ & $13.5 \pm 2.0$ & $12.0 \pm 2.1$ & $14.1 \pm 1.7$ & $<.0001$ \\
\hline Weight $(\mathrm{kg})$ & $83.3 \pm 18.9$ & $78.6 \pm 16.4$ & $85.3 \pm 19.6$ & .03 \\
\hline Height $(\mathrm{cm})$ & $174.7 \pm 11.2$ & $172.0 \pm 12.7$ & $175.8 \pm 10.4$ & .07 \\
\hline Body surface area $\left(\mathrm{m}^{2}\right)$ & $1.98 \pm 0.24$ & $1.91 \pm 0.23$ & $2.01 \pm 0.25$ & .01 \\
\hline $\begin{array}{l}\text { Total blood products (units, median } \\
\text { with } 25 \text { th-75th percentile) }\end{array}$ & $13(8-20)$ & $22(18-31)$ & $9(6-13)$ & $<.0001$ \\
\hline Recombinant factor VIIa & $3 \%(5)$ & $10 \%(5)$ & $0 \%(0)$ & $<.0001$ \\
\hline Aprotinin & $48 \%(81)$ & $48 \%(24)$ & $48 \%(57)$ & 97 \\
\hline Maximum aortic diameter $(\mathrm{cm})$ & $5.85 \pm 1.01$ & $6.04 \pm 1.19$ & $5.77 \pm 0.92$ & .14 \\
\hline Reoperation (resternotomy) & $27 \%(45)$ & $39 \%(21)$ & $21 \%(24)$ & .01 \\
\hline Emergency status & $24 \%(40)$ & $39 \%(20)$ & $17 \%(20)$ & .001 \\
\hline Crossclamp time (min) & $136.9 \pm 51.1$ & $142.2 \pm 57.3$ & $136.6 \pm 48.2$ & .38 \\
\hline Cerebral circulatory arrest time ( $\mathrm{min})$ & $22.2 \pm 7.4$ & $24.6 \pm 7.4$ & $21.1 \pm 7.1$ & .004 \\
\hline Systemic circulatory arrest time (min) & $28.0 \pm 19.6$ & $34.8 \pm 19.6$ & $25.1 \pm 17.4$ & .001 \\
\hline Cardiopulmonary bypass time (min) & $225.8 \pm 60.5$ & $248.7 \pm 85.8$ & $216.1 \pm 42.3$ & .01 \\
\hline Concomitant procedure & $22 \%(36)$ & $34 \%(17)$ & $16 \%(19)$ & .007 \\
\hline Location of aortic repair & & & & .004 \\
\hline Root or ascending only & $1.2 \%(2)$ & $2 \%(1)$ & $0.8 \%(1)$ & \\
\hline Arch involvement & $89 \%(150)$ & $82 \%(40)$ & $92 \%(110)$ & \\
\hline Total arch & $9.5 \%(16)$ & $16 \%(8)$ & $6.7 \%(8)$ & \\
\hline Descending or thoracoabdominal & $10 \%(16)$ & $20 \%(10)$ & $5 \%(6)$ & \\
\hline Blood cell salvage device volume $(\mathrm{mL})$ & $537 \pm 475$ & $715 \pm 663$ & $464 \pm 351$ & .01 \\
\hline 12-h chest tube drainage $(\mathrm{mL})$ & $664 \pm 568$ & $1050 \pm 864$ & $517 \pm 341$ & .0003 \\
\hline Taken back to operating room for bleeding & $6 \%(10)$ & $18.4 \%(9)$ & $0.84 \%(1)$ & $<.0001$ \\
\hline 30-d Mortality & $3.0 \%(5)$ & $4.1 \%(2)$ & $2.5 \%(3)$ & .09 \\
\hline
\end{tabular}

Categoric data are given as percentages, with the number of patients in parentheses and continuous data as mean $\pm \mathrm{SD}$, except as noted. $M T$, Massive transfusion.

analysis. Secondarily, we developed a logistic regression model for massive transfusion ( $\geq 5$ units of PRBCs) as a dichotomous outcome.

We identified 26 preoperative and procedural variables as being potentially related to blood product use. Univariate associations were assessed with 1-way analysis of variance for categoric variables and correlation tests for continuous variables. Race was defined as white versus nonwhite. Of the 26 variables, 16 had $P$ values lower than .05 when testing for a difference between the groups. These 16 variables were included in a backward stepwise procedure that eliminated nonsignificant variables individually until only significant variables remained. In this manner, a final predictive model was developed. To create the linear regression models for total blood products and CPB time, linear univariate association tests were used, with nonsignificant variables dropped from the multivariate model 1 at a time until only significant variables remained in the model.

Finally, with Pearson correlation coefficients, we conducted a post hoc assessment of the relationship of blood product transfusion with other metrics of perioperative bleeding by examining correlations with volume of processed blood (blood cell salvage machine) returned to the patient intraoperatively and chest tube drainage from time of intensive care unit arrival to 12 postoperative hours. We also evaluated the proportion of total blood products given during $\mathrm{CPB}$ to distinguish between anemia during $\mathrm{CPB}$ and continued bleeding after $\mathrm{CPB}$ as reasons for requiring transfusion. All statistical analyses were performed with SAS statistical software version 9.1.3 (SAS Institute Inc, Cary, NC).

\section{RESULTS}

\section{Patient and Operative Variables}

One hundred seventy thoracic aortic procedures with DHCA were performed during the period of study. Only two patients were excluded, both of whom had major blood loss and massive transfusion from another procedure in the perioperative period. Thus 168 thoracic aortic procedures were available for data abstraction and fulfilled selection criteria, representing a single-center, single-surgeon experience.

Figure 1 displays the use of the various blood products in the 168 study patients, with medians as well as upper and lower quartiles for PRBCs (median, 3 units; interquartile range [IQR], 1-6 units), platelets (3 units; IQR, 2-4 units), cryoprecipitate (0 units; IQR, 0-1 units), fresh-frozen 


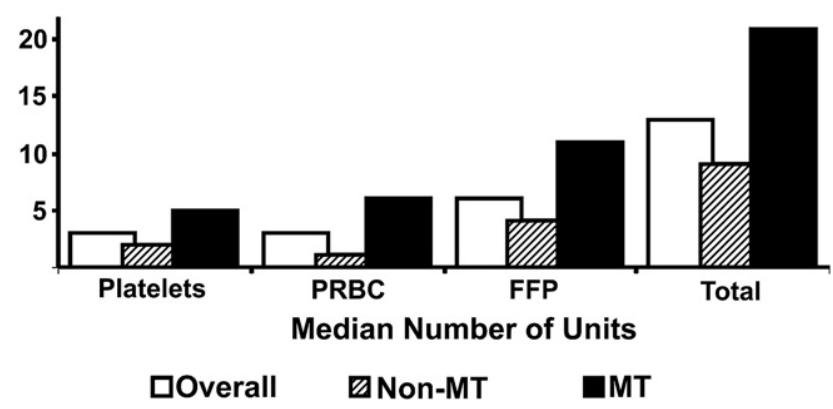

FIGURE 1. Blood products transfused. Note that y-axis values represent units of blood products, with total representing total units transfused. Cryoprecipitate is not included in graphic display because median number of units transfused was zero overall. PRBC, Packed red blood cells: FFP, freshfrozen plasma; Non-MT, no massive transfusion; $M T$, massive transfusion.

plasma (6 units; IQR, 4-10 units), and total blood products transfused (13 units; IQR, 8-20 units). We classified 49 patients $(29 \%)$ as having massive transfusion if they received at least 5 units of transfused PRBCs. The remaining 119 patients were classified as not receiving massive transfusion.

Table 1 describes patient and operative variables of the cohort and details a univariate comparison of characteristics from the massive transfusion and no massive transfusion groups. Of note, recombinant activated factor VII (NovoSeven; Novo Nordisk Inc, Princeton, NJ) was given to only 5 patients, all of whom had received massive transfusion (10\% of this cohort). Uses of the pharmacologic agents Coumadin (preoperatively, $20 \%$ vs $14 \%, P=.31$ ) and aprotinin (intraoperatively, $48.0 \%$ vs $48.4 \%, P=0.97$ ) were similar between the groups. Among the 40 emergency cases, none of the patients were taking clopidogrel preoperatively, and only 1 was taking aspirin at $325 \mathrm{mg}$ (aspirin at $81 \mathrm{mg}$ is not withheld before elective cases).

Overall, the type of aortic repair was root or ascending only in $1.2 \%$ ( $2 \%$ massive transfusion vs $0.8 \%$ no massive transfusion), hemiarch or total arch in $89 \%$ (82\% massive transfusion vs $92 \%$ no massive transfusion), with $9.5 \%$ being total arch (16\% massive transfusion vs $6.7 \%$ no massive transfusion), and descending or thoracoabdominal in $10 \%$ (20\% massive transfusion vs $5 \%$ no massive transfusion). The procedure was classified as resternotomy (reoperation) for $39 \%$ of the massive transfusion group, compared with $21 \%$ of the no massive transfusion group $(P=.01)$; there were no reoperative descending or thoracoabdominal aortic aneurysm procedures. Patients with massive transfusion were also more likely to undergo concomitant procedures $(34 \%$ vs $16 \%, P=.001)$ and more likely to have had emergency operations $(39 \%$ vs $17 \%$, $P=.001)$. The thirty-six cases with concomitant procedures included coronary artery bypass grafting $(\mathrm{n}=24$, $67 \%)$, maze $(n=3,8 \%)$, atrial septal defect repair $(\mathrm{n}=3,8 \%)$, and other $(\mathrm{n}=6,16 \%)$. The indication for emergency operation was acute type A aortic dissection in all cases. Aortic crossclamp times were equivalent between the groups (142 vs 137 minutes, $P=.38$ ), whereas systemic circulatory arrest time ( 35 vs 25 minutes, $P=.001$ ) and CPB time (249 vs 216 minutes, $P=.007$ ) were significantly longer in the massive transfusion group.

\section{Outcome Metrics}

Return to the operating room for bleeding was required in $6 \%$ of cases. The return rate for bleeding among the massive transfusion group was $18 \%$, versus $0.8 \%$ among the no massive transfusion group $(P<.0001)$. Of note, mean blood cell salvage machine volumes returned to patients intraoperatively were $715 \mathrm{~mL}$ in the massive transfusion group and $464 \mathrm{~mL}$ in the no massive transfusion group $(P=.01)$, and mean 12-hour chest tube drainage volumes were $1050 \mathrm{~mL}$ in the massive transfusion group and $517 \mathrm{~mL}$ in the no massive transfusion group $(P=.0003)$. Mortality at 30 days was $3 \%$ overall and was higher in the massive transfusion group $(4 \%)$ than in the no massive transfusion group $(2.5 \%)$.

The Pearson correlation coefficients were 0.43 $(P=0.001)$ between total blood products transfused and volume of salvaged blood cells returned intraoperatively and $0.54(P<.0001)$ between total blood products transfused and 12-hour chest tube drainage, while blood cell salvage machine volume and chest tube drainage had no association $(r=0.049, P=.55)$. The mean PRBC volume given during CPB was $1.3 \pm 2.1$ units (range, 0-16 units), compared with $3.9 \pm 4.7$ PRBC units (range, 0-26 units) given from procedure start time to 48 postoperative hours.

\section{Multivariate Models and Predictors}

The correlation coefficient for PRBC and total blood product transfusion was greater than 0.90 , with total blood products used as the primary, continuous outcome variable. The linear regression model is described in Table 2, with 6 significant variables independently associated with total blood product transfusion: age $(P=.008)$, preoperative hemoglobin $(P=.04)$, weight $(P=.02)$, CPB time $(P<.0001)$, emergency status $(P<.0001)$, and reoperation status $(P<.0001)$. The adjusted $R^{2}$ for this model was 0.42 , indicating that these variables accounted for $42 \%$ of the variability in blood products transfused.

The logistic regression model for the outcome massive transfusion is shown in Table 3 . The odds ratios for the outcome of massive transfusion are as follows: for every $1-\mathrm{g} / \mathrm{dL}$

TABLE 2. Multivariate linear regression model for log-transformed total blood products

\begin{tabular}{lcc}
\hline \multicolumn{1}{c}{ Variable } & Regression slope & $\boldsymbol{P}$ value \\
\hline Age & 0.009 & .008 \\
Preoperative hemoglobin & -0.05 & .04 \\
Weight & -0.006 & .02 \\
Cardiopulmonary bypass time & 0.004 & $<.0001$ \\
Emergency status & 0.52 & $<.0001$ \\
Reoperation & 0.47 & $<.0001$ \\
\hline
\end{tabular}

$$
\text { The Journal of Thoracic and Cardiovascular Surgery • May } 2011
$$


TABLE 3. Predictors of massive transfusion (logistic regression model)

\begin{tabular}{cccc}
\hline Variable & $\begin{array}{c}\text { Odds } \\
\text { ratio }\end{array}$ & $\begin{array}{c}\mathbf{9 5} \% \text { Wald } \\
\text { confidence } \\
\text { interval }\end{array}$ & $\begin{array}{c}\text { Predictor } \\
\boldsymbol{P} \text { value }\end{array}$ \\
\hline $\begin{array}{c}\text { Preoperative hemoglobin } \\
\text { (per 1-g/dL increment) }\end{array}$ & 0.543 & $0.428-0.688$ & $<.0001$ \\
$\begin{array}{c}\text { Cardiopulmonary bypass } \\
\text { time (per 10-min increase) }\end{array}$ & 1.15 & $1.05-1.26$ & .0026 \\
Emergency status & 4.02 & $1.532-10.553$ & .0047 \\
\hline
\end{tabular}

increase in preoperative hemoglobin, odds ratio was 0.54 (95\% confidence interval, $0.43-0.69 ; P<.0001$ ); for every 10-minute increase in CPB time, odds ratio was 1.15 (95\% confidence interval, 1.05-1.26; $P=.0026)$; and for emergency status, odds ratio was 4.02 ( $95 \%$ confidence interval, $1.53-10.55 ; P=.0047)$. Many procedural factors correlated with CPB time and therefore were not independent predictors of bleeding. These included crossclamp time, body surface area, concomitant procedure, and reoperation. The univariate associations with massive transfusion are be noted in Table 1. A multivariable regression analysis predicting CPB time $\left(R^{2}\right.$ for the model of 0.26$)$ showed that increased body surface area, concomitant procedure, and reoperation were all significant predictors (Table 4).

\section{DISCUSSION}

In this observational study of consecutive patients undergoing thoracic aortic procedures involving DHCA from 2005 through 2008, we were able to identify the patient and procedural characteristics associated both with overall blood product use and with massive transfusion. First, independent predictors of total blood products transfused included age, preoperative hemoglobin, weight, CPB time, and emergency status. Second, a logistic regression model determined massive perioperative transfusion to be independently predicted by 3 variables: preoperative hemoglobin level, CPB time, and emergency operation status.

An initial descriptive analysis of patient variables found that patients in the massive transfusion group tended to be older, smaller (lower preoperative weight and body surface area), and sicker (higher American Society of Anesthesiologists grade, lower preoperative hematocrit). Durations of CPB and of both systemic and cerebral circulatory arrest were longer for the massive transfusion group. Many of the variables showed expected univariate associations with

TABLE 4. Predictors of cardiopulmonary bypass time (linear regression model)

\begin{tabular}{lcccr}
\hline \multicolumn{1}{c}{ Variable } & $\begin{array}{c}\text { Regression } \\
\text { slope }\end{array}$ & SE & $\boldsymbol{t}$ Value & $\boldsymbol{P}$ value \\
\hline Body surface area & 49.56 & 16.85 & 2.94 & .0037 \\
Concomitant procedure & 53.70 & 10.24 & 5.24 & $<.0001$ \\
Reoperation & 35.30 & 9.766 & 3.61 & .0004 \\
\hline
\end{tabular}

blood product use, but collinearity of variables confounded persistence of independent association in a multivariate model. For example, although it was an independent predictor in the linear regression model, reoperation did not remain so in the final logistic regression model because it did not independently contribute to the model of massive transfusion more than did CPB time alone.

$\mathrm{CPB}$ time and emergency operation are recognized predictors of transfusion, ${ }^{2,3,5}$ and the time required to achieve DHCA further prolongs CPB time, likely causing platelet and enzyme dysfunction. ${ }^{1,3,7}$ The value of preoperative anemia as a prognosticator for adverse outcomes has been replicated by several groups ${ }^{11,15-17}$; however, previous studies have not examined anemia in a model for transfusion requirement in thoracic aortic surgery with DHCA. In our patient sample, hemoglobin may be a marker of broader physiologic reserve and consumption of platelets and coagulation factors by various aortic pathologies.

Several limitations should be considered when interpreting the findings of this study. First, this was a retrospective, observational study, for which causality cannot be inferred. The effects of unknown or unmeasured confounders on the observed associations cannot be excluded. A major limitation of other studies investigating predictors of perioperative blood loss in cardiac surgery has been that the investigations compared cases across different surgical, anesthesia, and intensive care unit teams, resulting in wide, unadjusted variation in surgical practices and perioperative management strategies. ${ }^{2,3,18}$ We reduced but did not eliminate surgical technique and institutional practice as confounders by reporting a large series of patients undergoing aortic surgery with DHCA conducted by a single surgeon and postsurgical care unit with a protocol-driven approach to transfusion.

Although this study represents the largest to date examining factors associated with transfusion in the DHCA population, a relatively large number of variables were determined a priori to be of clinical importance in considering predictors of massive transfusion, which increases the chance of a type II error. We chose not to use a principal components strategy to reduce the degrees of freedom by combining potential predictors because of the resulting inability to interpret individual coefficients. Also of note, a systematic change in the pharmacologic management of bleeding occurred during the study period. When aprotinin was officially removed from the US market in late 2007, patients received $\epsilon$-aminocaproic acid as an alternative agent, although aprotinin use was similar between those with and without massive transfusion.

This analysis did not discriminate between transfusion to treat anemia and that to treat bleeding. This could be regarded as a weakness or a strength of the design; we elected to evaluate overall transfusion requirements, because deleterious effects of transfusion are related to the total number of units transfused. For the same reason, we extended our outcome to transfusion in the perioperative period, rather than 
the day of surgery. Although there was a highly significant correlation between units of PRBCs transfused and both intraoperative bleeding (blood cell salvage machine volume transfused) and postoperative bleeding (chest tube drainage), approximately a third of the PRBC units transfused were given before separation from CPB to treat preexisting anemia, acute blood loss before $\mathrm{CPB}$, or hemodilution during $\mathrm{CPB}$. Intraoperative transfusions before closure of the chest have been excluded by other investigators on the basis of the premise that excessive bleeding during this part of the operation frequently reflects inadequate surgical hemostasis and may not reflect the hemostatic defect induced by $\mathrm{CPB} .^{2,3}$ Although deposition of platelets and circulating blood proteins, as well as nonsurgical bleeding related to graft porosity and needle hole injury, occur less with the polyethylene terephthalate (Dacron) graft material used in our series than with polytetrafluoroethylene and other graft materials, however, these interactions remain an important consideration. ${ }^{19}$ The use of large prosthetic vascular conduits and DHCA is unique to aortic surgery and has an immediate effect on the coagulation cascade, which would be lost to analysis without inclusion of intraoperative transfusions and the volume of salvaged blood cells returned intraoperatively, correlated closely with total blood product use.

Our model for predicting massive perioperative transfusion may allow more focused use of both established and novel strategies for reducing perioperative blood loss, including correction of hypothermia and perioperative pharmacologic interventions available for reducing the coagulation dysfunction associated with CPB and aortic surgery. ${ }^{20,21}$ Typical pharmacologic interventions have focused on antifibrinolytic agents but could also focus on intraoperative adjuncts for the prevention of platelet dysfunction ${ }^{7,22}$ or the promotion of hemostasis with fibrinogen concentrate ${ }^{21}$ or recombinant factor VII. ${ }^{23}$ The etiology of preoperative anemia in patients undergoing elective cardiac operations has been described, and it is suggested that in most cases the anemia is preventable. ${ }^{24}$ Specifically, diagnosis of chronic anemia and its correction through iron supplementation or erythropoietin ${ }^{25}$ for elective cases is worth investigating with further clinical studies.

\section{CONCLUSIONS}

Our data support a model of CPB time, emergency status, and preoperative hemoglobin as independent predictors of massive perioperative transfusion in thoracic aortic procedures involving DHCA. This finding creates an opportunity for clinical investigations directed toward targeted therapeutic maneuvers for high-risk patients.

\section{References}

1. Shore-Lesserson L, Reich DL, Silvay G, Griepp RB. Hemostasis in aortic and cardiothoracic surgery. J Cardiovasc Surg. 1997;12:232-7.

2. Despotis GJ, Filos KS, Zoys TN, Hogue CW Jr, Spitznagel E, Lappas DG. Factors associated with excessive postoperative blood loss and hemostatic transfu- sion requirements: a multivariate analysis in cardiac surgical patients. Anesth Analg. 1996;82:13-21

3. Parr KG, Patel MA, Dekker R, Levin R, Glynn R, Avorn J, et al. Multivariate predictors of blood product use in cardiac surgery. J Cardiothorac Vasc Anesth. 2003; 17:176-81.

4. Welsby IJ, Podgoreanu MV, Phillips-Bute B, Mathew JP, Smith PK, Newman MF, et al. Genetic factors contribute to bleeding after cardiac surgery. J Thromb Haemost. 2005;3:1206-12.

5. Wahba A, Rothe G, Lodes H, Barlage S, Schmitz G, Birnbaum DE. Predictors of blood loss after coronary artery bypass grafting. J Cardiothorac Vasc Anesth. 1997;11:824-7.

6. Harrington DK, Lilley JP, Rooney SJ, Bonser RS. Nonneurologic morbidity and profound hypothermia in aortic surgery. Ann Thorac Surg. 2004;78:596-601.

7. Kestin AS, Valeri CR, Khuri SF, Loscalzo J, Ellis PA, MacGregor H, et al. The platelet function defect of cardiopulmonary bypass. Blood. 1993;82:107-17.

8. Harker LA, Slichter SJ, Sauvage LR. Platelet consumption by arterial prostheses: the effects of endothelialization and pharmacologic inhibition of platelet function. Ann Surg. 1977;186:594-601.

9. Fisher DF Jr, Yawn DH, Crawford ES. Preoperative disseminated intravascular coagulation associated with aortic aneurysms. Arch Surg. 1983;118:1252-5.

10. ten Cate JW, Timmers H, Becker AE. Coagulopathy in ruptured or dissecting aortic aneurysms. Am J Med. 1975;59:171-6.

11. Karkouti K, Wijeysundera DN, Yau TM, Beattie WS, Abdelnaem E, McCluskey SA, et al. The independent association of massive transfusion with mortality in cardiac surgery. Transfusion. 2004;44:1453-62.

12. Unsworth-White MJ, Herriot A, Valencia O, Poloniecki J, Smith EE, Murday AJ, et al. Resternotomy for bleeding after cardiac operation: a marker for increased morbidity and mortality. Ann Thorac Surg. 1995;59:664-7.

13. Husain AM, ed. A practical approach to neurophysiologic intraoperative monitoring. New York: Demos Medical Publishing; 2008.

14. American Society of Anesthesiologists Task Force on Perioperative Blood Transfusion and Adjuvant Therapies. Practice guidelines for perioperative blood transfusion and adjuvant therapies: an updated report by the American Society of Anesthesiologists Task Force on Perioperative Blood Transfusion and Adjuvant Therapies. Anesthesiology. 2006;105:198-208.

15. Zindrou D, Taylor KM, Bagger JP. Preoperative haemoglobin concentration and mortality rate after coronary artery bypass surgery. Lancet. 2002;359:1747-8.

16. Cladellas M, Bruguera J, Comin J, Vila J, de Jaime E, Martí J, et al. Is preoperative anaemia a risk marker for in-hospital mortality and morbidity after valve replacement? Eur Heart J. 2006;27:1093-9.

17. De Santo L, Romano G, Della Corte A, de Simone V, Grimaldi F, Cotrufo M, et al. Preoperative anemia in patients undergoing coronary artery bypass grafting predicts acute kidney injury. J Thorac Cardiovasc Surg. 2009;138:965-70.

18. Society of Thoracic Surgeons Blood Conservation Guideline Task Force, Ferraris VA, Ferraris SP, Saha SP, Hassel EA 2nd, Hana CK, et al. Perioperative blood transfusion and blood conservation in cardiac surgery: the Society of Thoracic Surgeons and The Society of Cardiovascular Anesthesiologists clinical practice guideline. Ann Thorac Surg. 2007;83:S27-86.

19. Roald HE, Barstad RM, Bakke IJ, Roald B, Liber T, Sakariassen KS. Initial interactions of platelets and plasma proteins in flowing non-anticoagulated human blood with the artificial surfaces Dacron and PTFE. Blood Coagul Fibrinolysis. 1994;5:355-63.

20. Mannucci PM, Levi M. Prevention and treatment of major blood loss. $N$ Engl J Med. 2007;356:2301-11.

21. Rahe-Meyer N, Solomon C, Winterhalter M, Piepenbrock S, Tanaka K, Haverich A, et al. Thromboelastometry-guided administration of fibrinogen concentrate for the treatment of excessive intraoperative bleeding in thoracoabdominal aortic aneurysm surgery. J Thorac Cardiovasc Surg. 2009;138:694-702.

22. Tabata S, Yamaguchi S, Nagamine H, Tomita S, Arai S, Takemura H, Watanabe G. Efficacy of FK633, an ultra-short acting glycoprotein IIb/IIIa antagonist on platelet preservation during and after cardiopulmonary bypass. Eur J Cardiothorac Surg. 2004;26:289-93.

23. Gill R, Herbertson M, Vuylsteke A, Olsen PS, von Heymann C, Mythen M, et al. Safety and efficacy of recombinant activated factor VII: a randomized placebo-controlled trial in the setting of bleeding after cardiac surgery. Circulation. 2009;120:21-7.

24. Karski JM, Mathieu M, Cheng D, Carroll J, Scott GJ. Etiology of preoperative anemia in patients undergoing scheduled cardiac surgery. Can J Anaesth. 1999;46:979-82.

25. Weltert L, D'Alessandro S, Nardella S, Girola F, Bellisario A, Maselli D, et al. Preoperative very short-term, high-dose erythropoietin administration diminishes blood transfusion rate in off-pump coronary artery bypass: a randomized blind controlled study. J Thorac Cardiovasc Surg. 2010;139:621-6. 